\title{
A Rare Case of Otitis Media-Associated Polymicrobial Anaerobic Meningitis and Brain Abscess
}

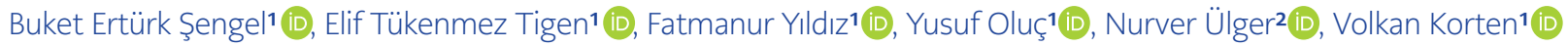 \\ 1 Infectious Disease and Clinical Microbiology, Marmara University Pendik Training and Research Hospital, İstanbul, Turkey \\ 2 Medical Microbiology, Marmara University Pendik Training and Research Hospital, İstanbul, Turkey
}

\begin{abstract}
Otitis media-associated complications are widespread when it is not treated with appropriate antimicrobial treatment. Meningitis and brain abscess are the most reported intracranial complications of otitis media, usually caused by the direct spread of organisms from the contagious site. While anaerobic microorganisms are well-known in brain abscesses, they are not common in meningitis. When the clinical history and pathogenesis of otitis mediaassociated meningitis are combined, special methods to identify and cover anaerobic pathogens should be considered.

Keywords: Anaerobic, meningitis, acute otitis media, brain abscess, polymicrobial
\end{abstract}

\section{INTRODUCTION}

A cute otitis media (AOM) primarily occurs in childhood. While the incidence of $\mathrm{AOM}$ is $45 \%$ to $60 \%$ in children under the age of five, this rate was 3.1 to 3.5 in adults aged 15-24 (1). The most common causative bacterial pathogens are Streptococcus pneumoniae, Haemophilus influenzae, and Moraxella catarrhalis. On the other hand, although anaerobes, mainly Gram-positive cocci, may be responsible for the infection, their roles are insignificant (2). Fusobacterium nucleatum and Treponema denticola were found in nasopharyngeal aspirates during AOM episodes (2). Polymicrobial infection is generally seen in chronic suppurative otitis media and reflects biofilm in the middle ear space.

There are many serious intracranial complications of otitis media (OM), such as mastoiditis, brain abscess, and meningitis (3). In the pre-antibiotic era, these complications occurred more and were resulted in fatal. Therefore, the appropriate antimicrobial treatment is the most crucial step.
Corresponding Author: Buket Ertürk Şengel

\section{E-mail: besengel@gmail.com}

Received: June 04, 2021 Accepted: September 28, 2021 Published: December 30, 2021

\section{Suggested citation:} Ertürk-Şengel B, TükenmezTigen E, Yıldız F, Oluç Y, Ülger N, Korten $\mathrm{V}$. A rare case of otitis media-associated polymicrobial anaerobic meningitis and brain abscess. Infect Dis Clin Microbiol 2021; 3: 164-167.

DOI: 10.36519/idcm.2021.54 
Here, we reported a case of acute otitis media-associated mastoiditis, brain abscess, and polymicrobial anaerobic meningitis in an adult patient.

\section{CASE PRESENTATION}

A 21-year-old female with no medical history was admitted to the hospital with fever, headache, and confusion in February 2019. She was non-cooperative and disoriented. She had suffered from pain and otorrhea in her left ear for two weeks. When she applied to another center, ciprofloxacin and amoxicillin-clavulanate were prescribed as ear drops. However, she did not use the drugs. On examination, body temperature was $38.2^{\circ} \mathrm{C}$, blood pressure 110/80 $\mathrm{mmHg}$, heart rate 123 beats/min, and respiratory rate 24 breaths $/ \mathrm{min}$. She has neck stiffness and purulent drainage in her left ear. She was intubated. Cranial computer tomography (CT) was revealed a collection in the pineal lodge and superior cerebellar cistern and diffuse hypoxic findings. Additionally, it showed loss of aeration on mastoid cells on the left and soft tissue densities in the middle ear cavity (Figure 1-2). After fundus examination, lumbar punction

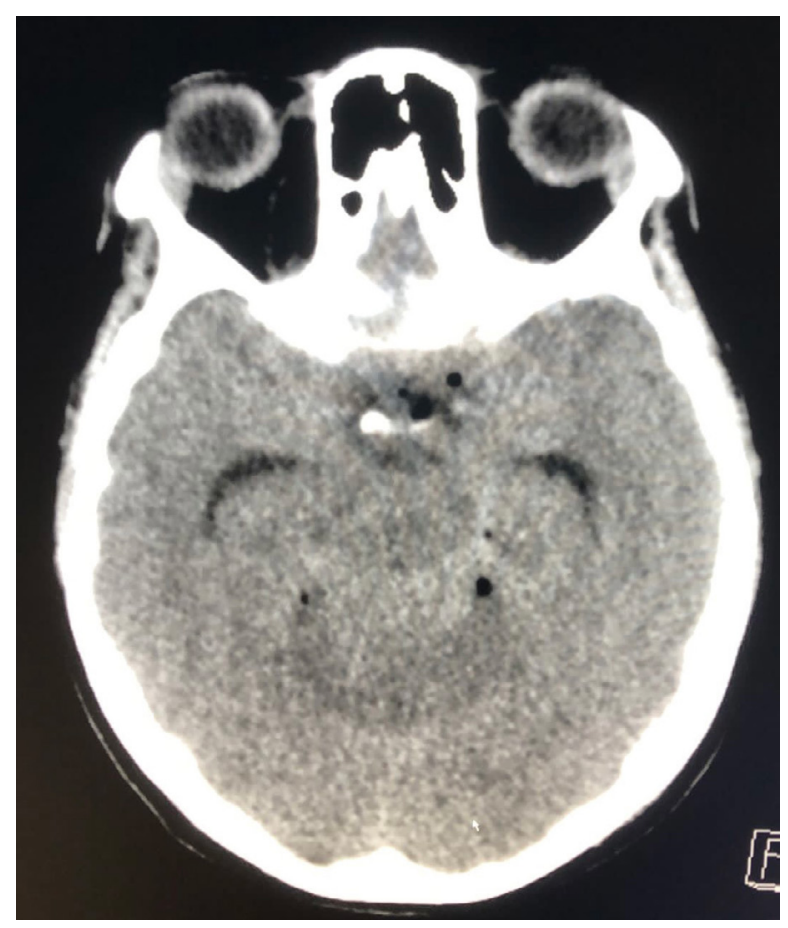

Figure 1. Collection in the pineal lodge and superior cerebellar cistern. was performed, and the appearance of cerebrospinal fluid (CSF) was purulent (Figure 3). On microscopic examination of CSF, clustered polymorph cells, Gram-negative bacilli, and Gram-positive cocci and cocobacilli were demonstrated (Figure 4). The CSF was cultured for aerobic and anaerobic organisms. The other CSF findings were as follows; total leucocyte count (TLC) of 112,318 / $\mu \mathrm{L}$ (polymorphonuclear 29\%, lymphomononuclear 71\%), protein $359 \mathrm{mg} / \mathrm{dL}$, glucose $1 \mathrm{mg} / \mathrm{dL}$, and simultaneous blood glucose level $163 \mathrm{mg} / \mathrm{dL}$. The BioFire® FilmArray ${ }^{\circledR}$ Meningitis/Encephalitis (ME) panel and Mycobacterium tuberculosis PCR was negative. The abscess could not be drained due to the poor condition of the patient. Intravenous (IV) ceftriaxone $2 \times 2 \mathrm{gm}$, vancomycin $2 \times 1$ $\mathrm{gm}$, metronidazole $3 \times 500 \mathrm{mg}$, and dexamethasone $0.15 \mathrm{mg} / \mathrm{kg}$ q6h were started immediately. The patient was admitted to the intensive care unit. Laboratory analysis revealed leukocytosis $(24,000 / \mu \mathrm{L})$, polymorphonuclear leukocyte (91\%), the elevation of procalcitonin $(7.86 \mu \mathrm{g} / \mathrm{L})$, and C-reactive protein (105 mg/L). Thorax CT revealed large consolidation areas with air bronchograms in the lower lobes of both lungs, and a tree-in-bud pattern was observed

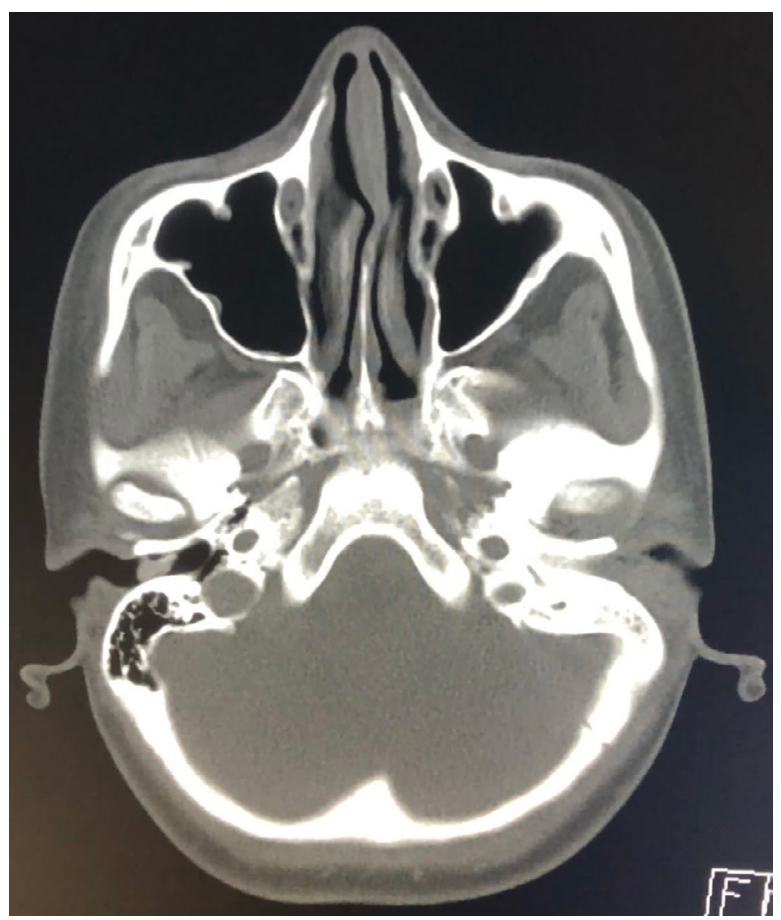

Figure 2. Loss of aeration on mastoid cells on the left and soft tissue densities in the middle ear cavity. 


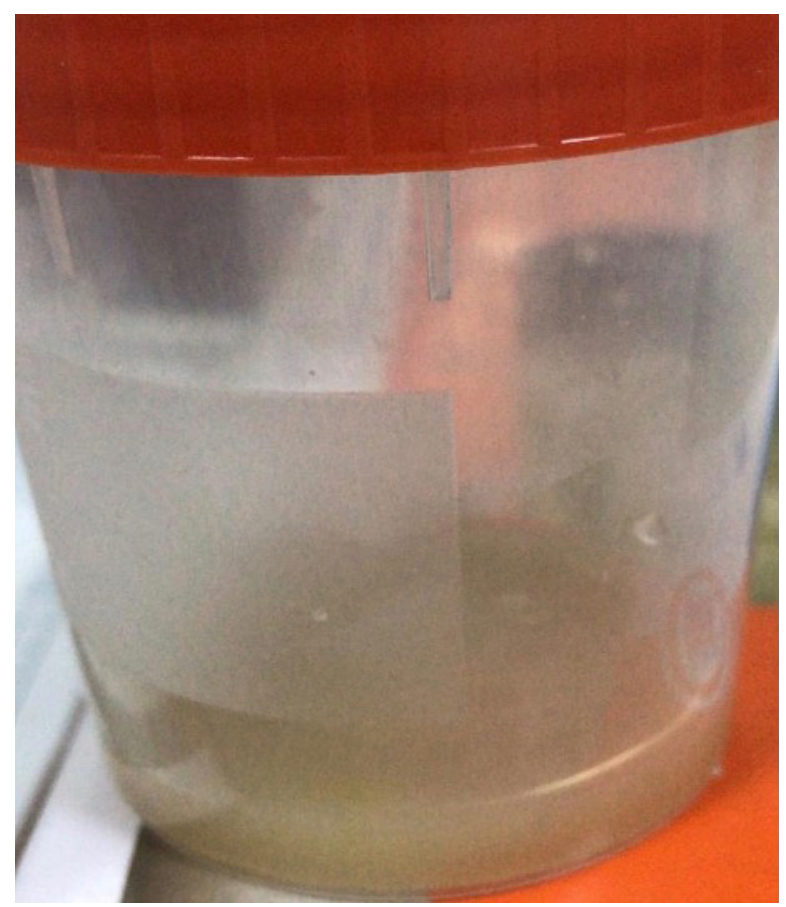

Figure 3. CSF macroscopic view.

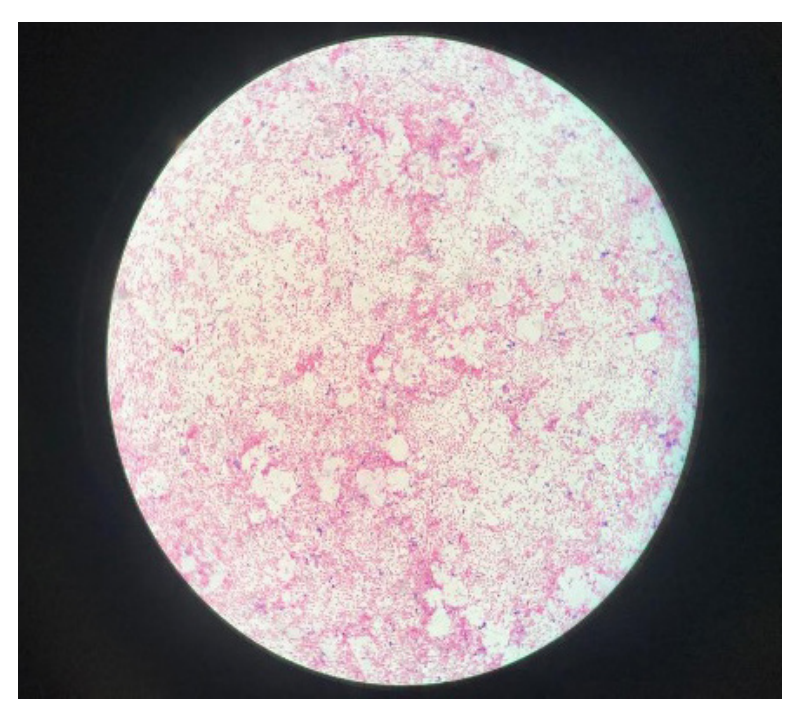

Figure 4. Direct examination; clustered polymorph cells, Gramnegative bacilli, Gram- positive cocci and cocobacilli.

in the upper lobe of the right lobe. Prevotella timonensis and Actinomyces europaeus, identified by MALDI-TOF MS (VITEK® MS; bioMérieux, Marcy l'Etoile, France) were cultured from CSF. The patient's clinical condition slightly worsened day by day. Thirteen days later, the brain death was determined.

\section{DISCUSSION}

Otitic meningitis and intracranial abscess are the most common intracranial complications of chronic otitis media (4). However, it may be related to $\mathrm{AOM}$ as well. In our report, although the patient had suffered from left ear pain and purulent discharge for two weeks, chronic otomastoiditis findings and abscess in the pineal lodge were observed in cranial CT. The causative microorganisms of $\mathrm{OM}$ are S. pneumoniae, H. influenzae, M. catarrhalis, Neisseria meningitidis, and group A streptococcus (5). In a study, in $27(42 \%)$ of 65 middle ear effusion samples, bacterial DNA was determined and in $10(37 \%)$ out of 27 were F. nucleatum. Only one sample was positive for F. nucleatum and T. denticola (6). These species are also the main anaerobes that are found in chronic otitis media (7).

Prevotella spp. and A. europaeus are normal constituents of the microbial flora in orodental infections. They can cause head-and-neck diseases, such as sinusitis and dental infections (8). Although they are a rare cause of bacterial meningitis, they can be observed more frequently in OM-associated meningitis. Although the pathophysiologic mechanism of otitic meningitis is not fully known, it is thought to be a direct extension through mastoid bone or hematogenous route (9). We also determined an intracranial abscess in our patient, and it is likely to direct the spread of organisms from the contagious site. However, we could not perform drainage of it because of patients' clinical situation. The microorganisms were cultivated from CSF in anaerobic culture. It is emphasized that anaerobic culture and specific diagnostic methods are critical before starting empirical antibiotic treatment.

While many of Prevotella spp. produce beta-lactamase, high-dose penicillins are recommended for Actinomyces species. Metronidazole, clindamycin or amoxicillin-clavulanate are appropriate for empirical treatment for anaerobic cervicofacial infection.

CSF penetration and bactericidal effect are crucial for antimicrobials, especially in central nervous system infections. Therefore, we immediately started ceftriaxone and metronidazole empirically in our case. Nevertheless, she passed away because of the late presentation. 


\section{CONCLUSION}

Our case is extraordinary because of having many serious complications of otitis media at the same time. Although the patient's history is not chronic, otitis media-associated mastoiditis, intracranial abscess, and polymicrobial anaerobic meningitis were observed. Additionally, this report demonstrated the importance of the anaerobic culture of CSF. Therefore, even if the patient has an acute history, intracranial complications should be kept in mind and cover anaerobic pathogens.
Ethical Approval: N.A.

Informed Consent: Written consent was obtained from the patient's relative.

Peer-review: Externally peer-reviewed

Author Contributions: Concept - B.E.S.., F.Y., Y.O.; Design B.E.Ş., E.T.T.; Supervision - N.Ü, V.K.; Materials - F.Y., Y.O., N.Ü.; Data Collection and/or Processing - F.Y., Y.O.; Analysis and/or
Interpretation - N.Ü., V.K.; Literature Review - B.E.S.., E.T.T.; Writer - B.E.Ş., E.T.T.; Critical Reviews - N.Ü., V.K.

Conflict of Interest: The authors have no conflict of interest to declare.

Financial Disclosure: The authors declared that this study has received no financial support.

\section{REFERENCES}

1 Monasta L, Ronfani L, Marchetti F, Montico M, Vecchi Brumatti L, Bavcar A, et al. Burden of disease caused by otitis media: systematic review and global estimates. PLoS One. 2012;7:e36226. [CrossRef]

2 Topcuoglu N, Keskin F, Ciftci S, Paltura C, Kulekci M, Ustek D, et al. Relationship between oral anaerobic bacteria and otitis media with effusion. Int J Med Sci. 2012;9:256-61. [CrossRef]

3 Lempinen L, Karppinen M, Pelkonen T, Laulajainen-Hongisto A, Aarnisalo AA, Sinkkonen ST, et al. Otitis media-associated bacterial meningitis in children in a low-income country. Pediatr Infect Dis. J 2019;38:791-7. [CrossRef]

4 Osma U, Cureoglu S, Hosoglu S. The complications of chronic otitis media: report of 93 cases. J Laryngol Otol. 2000;114:97100. [CrossRef]

5 Pichichero ME. Otitis media. Pediatr Clin North Am. 2013;60:391-407. [CrossRef]
6 Kulekci G, Ciftci S, Keskin F, Kilic AO, Turkoglu S, Badur S, et al. PCR analysis of Actinobacillus actinomycetemcomitans, Porphyromonas gingivalis, Treponema denticola and Fusobacterium nucleatum in middle ear effusion. Anaerobe. 2001;7:241-6. [CrossRef]

7 Brook I, Yocum P, Shah K. Aerobic and anaerobic bacteriology of concurrent chronic otitis media with effusion and chronic sinusitis in children. Arch Otolaryngol Head Neck Surg. 2000;126:174-6. [CrossRef]

8 Garcia M, Hirata M, Hossain N, Kunz A. Prevotella melaninogenica meningitis and abscess: Normal flora in an abnormal location. Pediatrics. 2018; 142 (1 Meeting Abstract) 602. [CrossRef]

9 Wetmore RF. Complications of otitis media. Pediatr Ann. 2000;29:637-46. [CrossRef] 